\title{
FABRICATION OF A MICRO TURBINE/BEARING RIG
}

\author{
Chuang-Chia Lin, Reza Ghodssi, Arturo A. Ayon, Dye-Zone Chen, Martin A. Schmidt \\ Microsystems Technology Laboratories and Gas Turbine Laboratory \\ Massachusetts Institute of Technology \\ Cambridge, MA 02139
}

\begin{abstract}
This paper reports on an effort to build a 5-level waferbonded micro-machined rotary machine. The device has been successfully fabricated through the use of aligned bonding, deep silicon etching, and laser-assisted etching of silicon. The preliminary spin testing of the micro turbine has demonstrated continuous operation at $30000 \mathrm{rpm}$.

\section{INTRODUCTION}

The first major fabrication challenge of realizing a miniature gas turbine generator is to demonstrate a baseline process capable of integrating the turbine rotor, bearings, and gas interconnects into a small package [1]. This structure, which we call the microbearing rig, not only validates a process methodology for fabrication of freely-rotating high aspect ratio devices, but it is also a vehicle for research into critical bearing stability issues. At MIT, we have developed a 5-wafer bonded device, which utilizes aligned wafer bonding, double-sided deep reactive ion etching (DRIE) by time-multiplexed deep silicon etching, and LaserAssisted-Etching (LAE) (Fig.1). The device is composed of a center wafer which contains the free silicon rotor and a journal bearing, and is capped from above and below by two pairs of wafers which provide fluidic interconnect and serve as thrust bearing surfaces.
\end{abstract}

\section{FABRICATION PROCESS}

The process flow involves the use of 5 wafers, 16 masks, and 9 deep silicon etching steps. A schematic illustration of the process is shown in figure 2 . The fabrication starts by etching shallow global alignment marks on both sides of all wafers. Next, two shallow patterns are etched to depths of $1 \mu \mathrm{m}$ and $4.5 \mu \mathrm{m}$, which define a thrust bearing gap and blade clearance in a first wafer, called the Forward End Plate (FEP). This is followed by a deep silicon etch on the opposite side of the wafer to a depth of $350 \mu \mathrm{m}$. This deep etch process, first developed by Bosch, has been exhaustively characterized, and is reported elsewhere in this meeting [2]. Next, the FEP wafer is inverted, a lithography operation is performed, and the wafer is reversably attached to a second carrier wafer (using a resist bond) and deep etching is performed to etch through the wafer to the deep features on the front surface. This wafer is fusion bonded to a second wafer, called the rotor plate (RP), which has been etched to a depth of $200 \mu \mathrm{m}$ to define turbine blades. Following a lithography operation on the RP to define a journal bearing, the RP/FEP pair is deep etched to fully define the rotor (using the reversable bond process described earlier). In principle, the rotor at this point is free, however, tabs have been created in the process of fabricating the FEP which bond to the rotor and hold it in place. These tabs will be removed by laser-assisted etching once the rotor is contained from above and below by the end plates. The process proceeds with the fabrication of an Aft End Plate (AEP), which is similar in process to the FEP, and a Forward Foundation Plate (FFP) and Aft Foundation Plate (AFP), which provide fluidic interconnect. The AEP and AFP are fusion bonded together, after which this pair is bonded to the RP/FEP pair, and then bonded to the FFP, completing the stack. (Fig.3) The 5-level stack is sawed into $1.5 \mathrm{~cm}^{2}$ dies and immersed in diluted HF to remove any surface oxide that will prevent proper etching during LAE. A focused argon laser beam then heats the tabs that held the rotor to near melting point in a chlorine flowing chamber. The heated silicon volume reacts with chlorine to form volatile silicon tetrachloride that is carried away by the flow. [3] The rotor is freed once the tabs are completely removed, and this concludes the micro bearing rig fabrication process.

\section{RESULTS}

In order for the rotor to reach the design speed, it is critical to keep the rotor lubricated by a continuous fluid film. This is accomplished by a set of bearings - a pair of hydrostatic thrust bearings keeps the rotor centered axially, and a journal bearing provides lateral supports to prevent wall strikes. [4] In start-up, the thrust bearings are pressurized so that the rotor is floating axially, then the main turbine air is supplied to turn the turbine rotor. Preliminary test results show a continuous operation at speed of about 30000rpm. (Fig 4) Fluctuations in rotor speed are observed, and we are currently investigating the origins of this effect, as well as exploring means to stablly increase the rotor speed.

\section{CONCLUSIONS}

In this paper we demonstrated a process to fabricate a micro bearing rig using bonding and deep silicon etching. The process can be applied to many areas to build devices with complicated micro fluid interconnects. The micro rotary machinery will also open new opportunities for fabricating micro valves, pumps, micro coolers, and micro propulsion devices.

\section{ACKNOWLEDGEMENT}

The authors would like to thank U.S. Army Research Office (Dr. R. Paur) for sponsoring this project. Gratitude also goes to the whole microengine team at MIT.

\section{REFERENCES}

1. A. H. Epstein, S.D. Senturia, et. al. "Power MEMS and Microengines", IEEE Transducer 97.

2. A. A. Ayon, C.-C. Lin, R. A. Braff, R. Bayt, H.H. Sawin and M. A. Schmidt, "Etching Characteristics and Profile Control in a Time Multiplexed Inductively Coupled Plasma Etcher", 1998 Solid-State Sensor and Actuator Workshop.

3. T. Bloomstein, "Laser Microchemical Etching of Silicon" Ph.D. Thesis, MIT (1996).

4. E.S. Piekos, D. J. Orr, S.A. Jacobson, F.F. Ehrich, and K.S. Breuer, "Design and Analysis of Microfabricated High Speed Gas Journal Bearings", $28^{\text {th }}$ AIAA Fluid Dynamics Conference, June 29-July 2, 1997. 
Wales

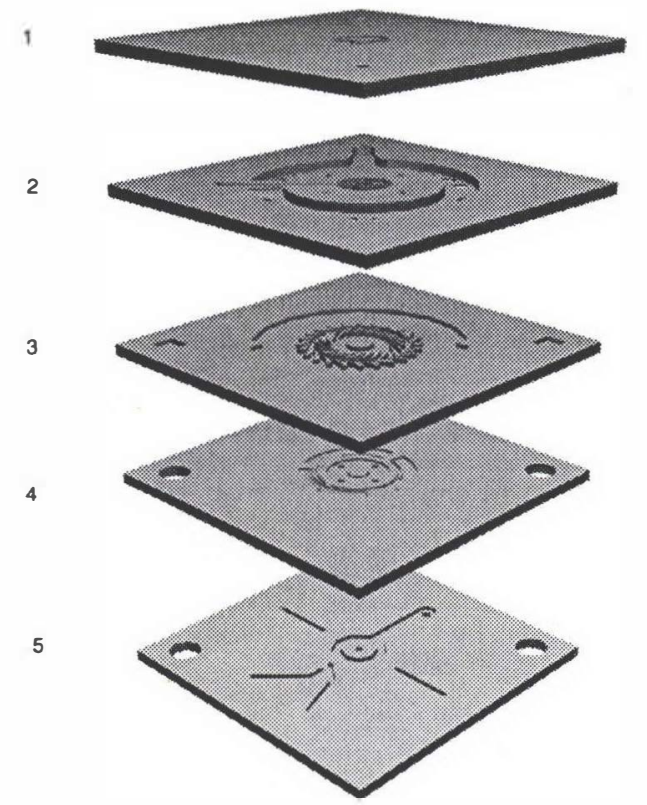

Figure 1 Exploded view of the micro bearing rig. The five layers are: 1. Forward foundation plate (FFP), 2. Forward endplate (FEP), 3. Rotor plate (RP), 4. Aft endolate (AEP). and 5. Aft foundation olate (AEP).

\section{FEP, 1st deep RIE}

\section{ए, ए2,}

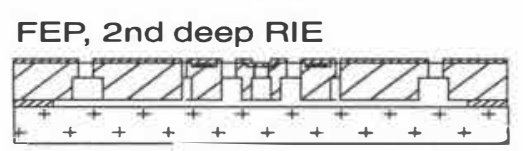

\section{FEP, finished

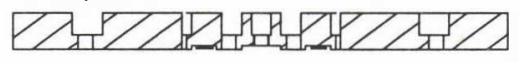

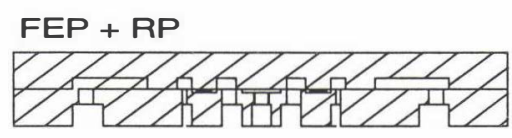

\section{DRIE rotor journal bearing}
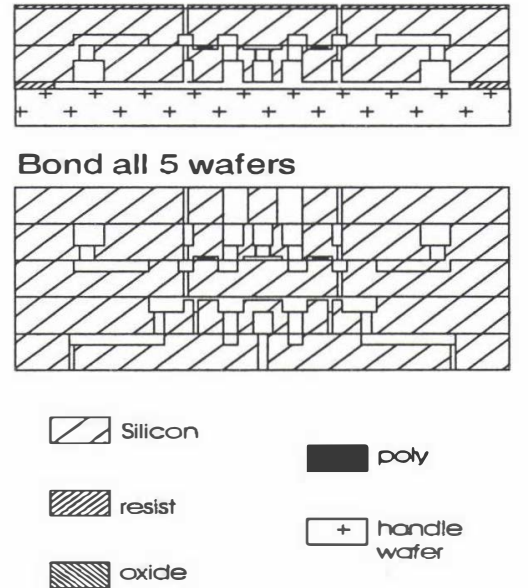

Figure 2 Micro Bearing Rig Fabrication Process

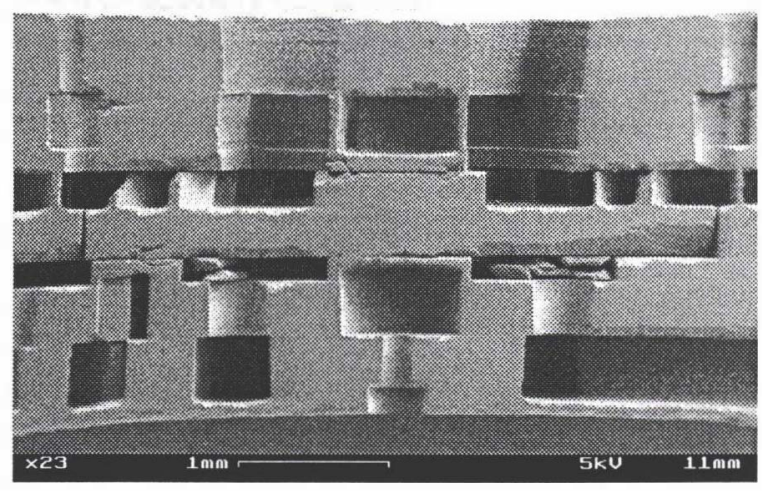

(a)

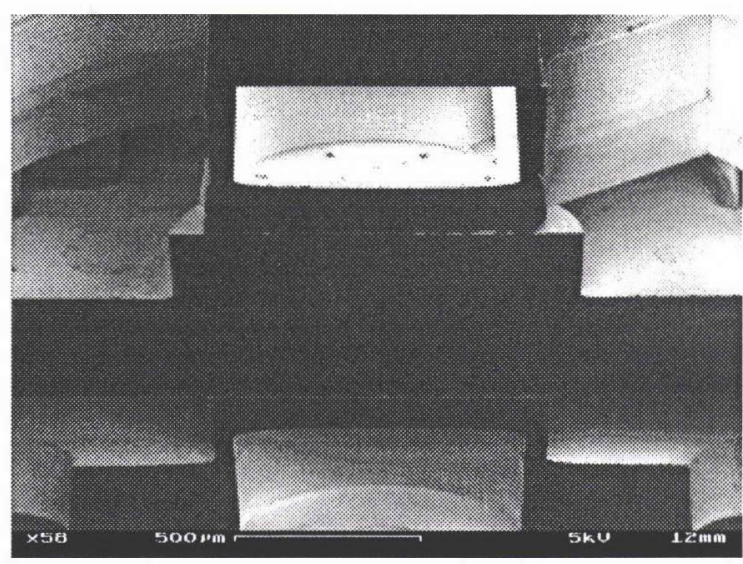

(b)

Figure 3 (a) SEM of micro bearing rig cross section. (b) Close view of micro rotor thrust bearings.

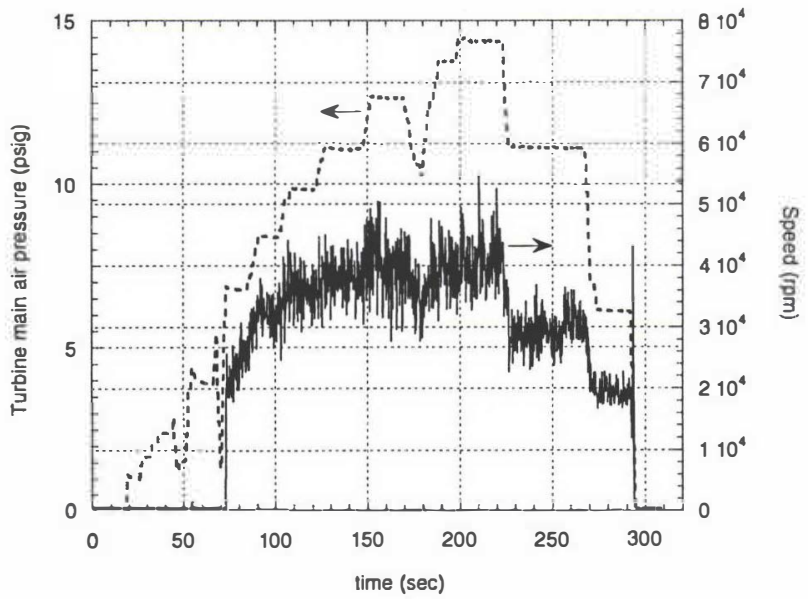

Figure 4 Rotor spin test result showing rotor speed increases with turbine main flow pressure. 